\title{
Inovação e pós-graduação: um estudo específico sobre o primeiro mestrado profissional em Educação na Bahia
}

\section{Graduate study and innovation: a study of the first professional master's program in education Bahia}

\section{Innovación y posgrado: un estudio específico sobre la primera maestría en Educación en Bahía}

Fabiana dos Santos Nascimento, mestre em Educação e Contemporaneidade pela Universidade do Estado da Bahia (Uneb). Endereço: Setor A, Rua Delmiro Gouveia, n 5, Cajazeira 8 - Cajazeiras. CEP: 41330-020 - Salvador, BA. Telefone: (71) 32199411/8709-8456. E-mail: fabi30_nascimento@hotmail.com.

Maria Gabriela Rodrigues Piñeiro, formada em Comunicação Social pela Universidade Católica de Salvador (UCSal). Endereço: Rua Arquimedes Gonçalves, n 153, apto. 404. CEP: 40050-300 - Salvador, BA. Telefone: (71) 3322-0472/9134-6258. E-mail: magapineiro@gmail.com.

Isabele Sodré Ramos, mestranda em Educação e Contemporaneidade pela Universidade do Estado da Bahia (Uneb). Endereço: Av. Cardeal Brandão Vilela, Cond. Recanto Verde, Bloco 232A, apto 102 - Mata Escura. CEP: 41219-600 - Salvador, BA. Telefone: (71) 3032-6324/8803-5193. E-mail: belesodre@gmail. com.

\section{Resumo}

O presente artigo é oriundo de um estudo realizado pela Agência Uneb de Inovação da Universidade do Estado da Bahia (Uneb) acerca do Mestrado Profissional em Gestão e Tecnologias Aplicadas à Educação (Gestec/Uneb). A apresentação deste estudo tem o objetivo de discutir a relação entre a inovação e o mestrado profissional (MP), em especial 
- Gestec, evidenciando-o como o primeiro mestrado profissional na área de Educação na Bahia. Para isso, será esboçado um panorama sobre o mestrado profissional na contemporaneidade, delineando os caminhos que levaram ao seu surgimento. Ademais, o texto traz algumas contribuições sobre as potencialidades inovadoras do MP, a fim de debater os pontos basilares dessa modalidade de mestrado no que tange à inovação no cenário educacional.

Palavras-chave: Mestrado Profissional. Inovação. Educação.

\section{Abstract}

This article is from a study conducted by the Agency UNEB Innovation at the University of the State of Bahia - UNEB about the Professional Masters in Management and Technology Applied to Education (GESTEC / UNEB). The study aims to discuss the relationship between innovation and the Professional Masters (MP), especially the GESTEC program, showing it to be the first Professional Masters in Education in Bahia. It provides an overview of the professional master's degree in contemporary society, outlining the factors that led to its emergence. In addition, the text offers a contribution pertaining to the innovative potential of the MP by discussing the basic points of this type of master's with respect to innovation in the educational setting.

Keywords: Professional Master. Innovation. Education.

\section{Resumen}

Este artículo es resultado de un estudio realizado por la Agencia UNEB de Innovación de la Universidad del Estado de Bahía (UNEB) acerca de la Maestría Profesional en Gestión y Tecnologías Aplicadas a la Educación (GESTEC/UNEB). La presentación de este estudio tiene como objetivo analizar la relación entre la innovación y la maestría profesional (MP), especialmente GESTEC, destacándolo como la primera 
maestría profesional en Educación en Bahía. Por esto, se hará una exposición general de la maestría profesional en la contemporaneidad, trazando los caminos que llevaron a su surgimiento. Además, el texto trae algunas contribuciones sobre el potencial innovador de la MP para discutir los pilares de esta modalidad de maestría en lo que se refiere a la innovación en el ámbito educativo.

Palabras clave: Maestría Profesional. Innovación. Educación.

\section{Introdução}

As reflexões contidas neste artigo são oriundas de estudos e pesquisas realizados na Agência Uneb de Inovação, o Núcleo de Inovação Tecnológica (NIT) da Universidade do Estado da Bahia. A iniciativa de relacionar a pós-graduação, em especial o mestrado profissional (MP), com a inovação tem como motivação, a priori, o fato de a agência estar alocada na Pró-Reitoria de Pesquisa e Ensino de Pós-Graduação da referida instituição, possibilitando que a equipe estabeleça um contato constante com a dinâmica, as necessidades e as possibilidades desse nível de ensino no que tange à inovação.

Outro ponto a salientar é a importância do debate atual sobre os mestrados profissionais e o crescimento da oferta desses cursos nos últimos anos, o que vem gerando intensas discussões e produções (MOREIRA, 2004; FISCHER, 2003, 2005, 2010; CASTRO, 2005; AGOPYAN; LOBO, 2007; BARROS, 2008; MARTINS; ASSAD, 2008; NEGRET, 2008; RIBEIRO, 2010; FREITAS, 2011; entre outros) que nos ajudam a compreender o processo de criação dessa modalidade de mestrado, além de apresentarem diferentes perspectivas, conceitos e lacunas presentes nesse processo. Para tratar das questões que permeiam, a nosso ver, a relação entre MP e inovação, convidamos para este debate autores como Morin (2005), Araújo (2007), Santos (2003), Lima Jr (2007), entre outros.

Essas interlocuções permitirão, ao longo do texto, atingir o objetivo maior deste trabalho, que é tratar da relação entre inovação e 
MP, suscitando reflexões pertinentes sobre as potencialidades geradas por essa integração.

A inovação é tratada na Lei n 10.973, de 02.12.2004 - Lei Federal de Inovação-, considerada, no capítulol, artigo $2^{\circ}$, inciso IV, como “introdução de novidade ou aperfeiçoamento no ambiente produtivo ou social que resulte em novos produtos, processos ou serviços" (BRASIL, 2004). Nesse sentido, podemos avaliar a importância da pesquisa e dos projetos desenvolvidos na universidade para a geração de inovação, seja por meio do empreendedorismo social, que prevê a participação efetiva da comunidade, seja por meio do empreendedorismo voltado à indústria e ao empresariado, considerando que ambos precisam conceber a inovação como instrumento que, essencialmente, deve estar a serviço da sociedade como um todo. Destacamos ainda o caráter social da Uneb, cuja tradição na área de Educação e a multicampia permitem uma significativa contribuição para o desenvolvimento regional.

De acordo com a nossa observação enquanto NIT, parte dos pesquisadores tem encontrado dificuldades para vislumbrar a inovação em áreas como Ciências Humanas, Linguística, Artes e Letras, Ciências Sociais, entre outras, por conta de uma cultura que concebe a inovação apenas entre as Ciências Exatas e as Engenharias e por lacunas deixadas pela legislação atual. Em nossos estudos, procuramos desvendar as possibilidades de inovação relacionadas às diversas áreas do conhecimento, à luz da interdisciplinaridade, salientando essa característica como fundamental à estrutura de grande parte dos mestrados profissionais, modalidade de curso sobre a qual nos debruçaremos neste artigo.

\section{Mestrado profissional: debates e perspectivas}

Pode-se dizer que o mestrado profissional é um modelo de curso de pós-graduação stricto sensu ainda incipiente no cenário brasileiro, enquanto prática institucional na universidade (FISCHER, 2005). No percurso em busca de se estabelecer, o MP tem encontrado 
tanto o incentivo de setores econômicos e sociais quanto a resistência dentro do próprio ambiente acadêmico.

No entanto, se fizermos uma retrospectiva dos desdobramentos da pós-graduação no Brasil, perceberemos que a intenção de criar cursos dessa natureza é antiga. Conforme observa Fischer, "a ideia de cursos orientados à capacitação profissional está expressa no parecer $n^{\circ}$ 977/65, do então Conselho Federal de Educação, que já propunha a criação de cursos de pós-graduação orientados à formação de profissionais" (2005, p. 25).

Desde quando a pós-graduação brasileira começou a se desenvolver na década de 1960 com os primeiros cursos lato sensu, o enfoque principal foi a formação voltada para o ensino superior e a pesquisa científica, o que se prolongou até o surgimento dos cursos stricto sensu nas décadas de 70 e 80, consolidando-se ao longo dos anos como tradição na universidade (Idem).

Aproximadamente na metade da década de 90, em um Brasil inspirado pela realidade americana e que tentava acompanhar a expansão capitalista oriunda do dito primeiro mundo, já surgiam cursos voltados especificamente para o mercado de trabalho. Nesse sentido, um modelo que ganhou projeção e se tornou bastante procurado na época foi o chamado MBA (Master Business Administration), especialização em Administração configurada como pós-graduação lato sensu que não titula o profissional como mestre, mas propunha uma visão mais global. Sob essa perspectiva, o MBA logo foi sendo adaptado a outras áreas do conhecimento e ressignificado de acordo com a competência esperada do profissional em cada setor (/dem).

Enquanto isso, assim como relatou a então coordenadora geral de Avaliação e Acompanhamento da Capes, a professora Maria Auxiliadora da Silva Campos Dessen, no IV Encontro do Fórum Nacional dos Mestrados Profissionais em abril de 2008,

[...] houve um reconhecimento por parte da CAPES da necessidade de formação de outro perfil profissional, devido a diversos fatores, como expansão e diferenciação dos sistemas produtivos, a extrema 
competitividade nos mercados de produtos e serviços, a globalização e exigências dos mercados externo e interno, entre outros (2008, p. 05).

Nesse movimento, caracterizado por novas demandas de mercado, o mestrado profissional teve a sua regulamentação aprovada em 1995, mas só a partir da Portaria $n^{\circ}$ 80, promulgada em 16 de dezembro de 1998, é que a modalidade de curso foi reconhecida pela Capes (CAPES, 1999).

Desde então, o MP passou a atrair ainda mais os interesses dos diversos setores sociais com os quais interagia. O número de cursos submetidos e aprovados pela Capes seguiu uma crescente (Gráfico 1 - Anexo). Em 1998, havia 24 cursos aprovados; em 2008, esse número cresceu para 225; atualmente, de acordo com o Portal da Capes (www.capes.gov.br), existem 398 cursos de MP recomendados e reconhecidos, o que representa um aumento médio de 16,6\% de cursos aprovados ao ano. Em relação ao mestrado acadêmico, o Portal da Capes registra atualmente 1.233 cursos reconhecidos.

Diante da expansão dos MP e das dificuldades inicialmente observadas, houve naturalmente a necessidade de se discutirem os caminhos desse novo modelo de curso. Por isso, originou-se o Fórum Nacional dos Mestrados Profissionais:

[...] foi instituído no dia 5 de maio de 2006, visando um diálogo permanente entre os coordenadores dos mestrados profissionais do país e os representantes da CAPES e da sociedade civil organizada. Os Encontros Nacionais ocorrem periodicamente para avaliar e propor ações que visem construir a excelência e a sustentabilidade dessa nova modalidade de mestrado da pós-graduação brasileira (www.fnmp.org. br/encontros).

As questões levantadas nesses encontros, até então, tratavam do teor inovador dos MP, da sustentabilidade aliada ao financiamento desses cursos, do tipo de avaliação a que eram submetidos, entre outras questões, o que sugeria à Capes uma forma diferenciada de lidar com essa modalidade de curso, considerando os aspectos específicos que norteiam todo o processo, desde a criação de um projeto até a própria gestão e o acompanhamento deles. O evento supracitado já realizou 
sete edições até o momento e deu margem à criação de outro evento, dessa vez, possibilitando encontros em que o público concentra-se entre os coordenadores de MP.

Com base no já mencionado relatório do IV Encontro do Fórum dos MP, destacamos que:

[...] foi em 2006 que ocorreu o estabelecimento de condições fundamentais para sua expansão e consolidação. As principais dificuldades apontadas nesse processo foram a objeção inicial da grande maioria dos representantes de área, a falta de entendimento sobre um perfil desses cursos, a falta de um entendimento sobre como avaliá-los e a inadequação dos instrumentos e mecanismos do sistema de avaliação para captar a realidade desses cursos (DESSEN, 2008, p. 5).

O modo de avaliação dos MP foi sempre muito questionado pelos coordenadores e docentes dos cursos de pós-graduação, que visam apontar saídas para uma melhoria nesse sentido.

Apesar da resistência de uma parcela da academia em validar o mestrado profissional, há um esforço no sentido de afirmar sua identidade enquanto categoria de curso de pós-graduação com estrutura basilarmente inovadora, ao passo que contribui para o processo de inovação', haja vista seus entrelaces com os movimentos extra- acadêmicos.

O momento atual impõe uma revisão de conceitos, uma vez que as transformações a nível global, o avanço vertiginoso das tecnologias e as exigências de um mercado empresarial e industrial competitivos tencionam as relações da universidade com os atores externos e despertam nos profissionais o interesse por uma especialização diferenciada e múltipla e por um conhecimento mais aplicável, que se distancia do modelo acadêmico tradicional. Além de adquirir o título de mestre, o aluno oriundo do MP pode lecionar e ainda tem a opção de ingressar em um doutorado, em alguns casos podendo terminar o curso em apenas um ano.

É importante observar que até pouco tempo atrás a formação superior era basicamente orientada por um pensamento cartesiano, ou seja, baseada na fragmentação do saber.
1 A palestra mencionada no relatório do IV Encontro do Fórum Nacional dos MP foi extraída da mesa 2: Parâmetros de Avaliação dos Mestrados Profissionais no Sistema de Pós-Graduação, proferida pela prof ${ }^{a}$ Maria Auxiliadora da Silva Campos Dessen. 
O mestrado profissional pressupõe pesquisadores com uma visão macro, que os permita transitar por diferentes áreas do conhecimento, devido ao caráter multirreferencial e interdisciplinar do curso. Desse modo, os profissionais são estimulados a buscarem soluções para questões complexas, aprendendo a superar na prática as limitações da sua formação de origem, enquanto interagem com novos saberes. Com um objetivo/tema em comum, a integração entre os saberes é facilitada, exigindo uma cooperação entre os profissionais das disciplinas envolvidas:

[...] num processo multidisciplinar, quando as relações de interdependência entre as disciplinas emergem é que se passa a ter interdisciplinaridade. Migra-se do simples intercâmbio de ideias a uma cooperação entre as disciplinas que pode gerar compenetração delas. A interdisciplinaridade constrói essa ligação entre o que era estanque e fechado para o que conversa, que coopera, que se mescla na busca de uma solução melhor do que a fornecida pelo isolamento (PALMADE apud HOFF et al., 2007, p. 46).

São profissionais com esse perfil multifacetado e empreendedor, hábeis em buscar resultados aplicáveis para as empresas e atentos às demandas da sociedade atual, que representam o perfil qualificado para contribuir com o processo de inovação (MARTINS; ASSAD, 2008).

Em uma visão interna à universidade, de um modo geral, percebe-se que apenas alguns departamentos ou grupos de pesquisadores isolados mantêm relações com o empresariado público ou privado. Isso ocorre pelo fato de a cultura da inovação ainda não ter se popularizado no ambiente acadêmico, havendo também pesquisadores que não veem com bons olhos essas relações com o meio externo, talvez por um senso de preservação da identidade acadêmica tradicional. Sobre isso, Martins e Assad (2008, p. 342) trazem:

Normalmente, esses programas mais dinâmicos tendem a serem vistos como "balcões de negócios" pelos seus pares, e, em alguns casos, já sofreram hostilidades de vários setores da universidade. [...] falta a disseminação de uma cultura empreendedora e da inovação no contexto da universidade e que essa seja uma política incorporada nas diretrizes estratégicas das instituições de ensino e pesquisa. 
Essa situação se apresenta como desafio aos Núcleos de Inovação Tecnológica (NIT²), já presentes em muitas universidades do País. No nosso caso, o desafio é dirigido à Agência Uneb de Inovação. $A$ priori, é preciso tornar a agência conhecida na comunidade acadêmica da Uneb, vencendo as limitações impostas pela sua multicampia, para que se possa então intensificar as ações de estímulo ao empreendedorismo e divulgar amplamente as vantagens da inovação para o País, bem como os instrumentos disponiveis para esse processo, quais sejam, informações sobre propriedade intelectual, projetos e procedimentos a adotar, em uma linguagem acessível a todos os envolvidos.

Ademais, essa mudança de modelo requer um esforço de toda a comunidade acadêmica no sentido de reconhecer a importância de adentrar efetivamente na era da inovação e de renovar processos defasados que interferem no sucesso dos empreendimentos. É notório que há "a necessidade de se reduzir o aparato burocrático existente hoje nas instituições de ensino e pesquisa, que, muitas vezes, oneraram o processo de parcerias, aumentando os custos de transação e promovendo atrasos na implementação de pesquisas e projetos conjuntos" (Ibidem, p. 341).

No entanto, cabe salientar que os incentivos à inovação têm aumentado significativamente no País, e que esse crescimento está vinculado, em grande parte, às demandas oriundas do desenvolvimento e à estabilidade econômica vislumbrada tanto pelo Estado como pelos diversos setores produtivos. Podemos destacar entre esses incentivos aqueles disponibilizados pelo governo em diferentes instâncias. São eles: (a) subsídios diretos: esse tipo de apoio dado pelo governo permite a ele definir quais serão os setores ou as atividades que receberão o incentivo; normalmente, esse tipo de auxílio é oferecido a setores que desenvolvem a interação entre pesquisa pública e privada e que não apresentam resultados imediatos; e (b) incentivos fiscais: os considerados apoios indiretos são estabelecidos por meio de créditos tributários e/ou cessão fiscal, alcançando, normalmente, maiores impactos, pois têm um custo menos elevado e são passíveis de obtenção de resultados a curto prazo (PACHECO, 2010).

2 Segundo Martins e Assad, "[...] os denominados NIT's teriam dentre suas diversas atribuições promover ações de proteção do conhecimento gerado nessas instituições, levar este conhecimento para o segmento empresarial e, principalmente, difundir o conceito e a prática do processo da inovação" (2008, p. 329). 
Paralelo aos incentivos remetidos ao setor privado, muito tem se feito legalmente para garantir o crescimento da inovação no País e isso ocorre pela incorporação do tema nas políticas públicas, gerando a atualização e a criação de novas leis que subsidiam tanto a participação de agentes públicos como de agentes privados no processo de inovação. A saber: (a) Lei de informática (11.077/04); (b) Lei de Inovação (10.973/04); (c) Lei do bem (11.196/05); e (d) Lei Rouanet da Pesquisa (11.487/07). Vale ressaltar que, além dos dispositivos legais de abrangência federal já citados, existem também instrumentos específicos para os estados e os municípios, assim como as leis de proteção à propriedade intelectual ${ }^{3}$.

As informações acima foram apresentadas para esboçar brevemente o panorama da inovação no cenário atual. Contudo, é importante lembrar que a inovação é tratada nesse trabalho por meio de um ponto de vista mais amplo, relativo ao sentido da novidade não atribuída unicamente à produção do lucro, mas relacionada ao aprendizado e às possibilidades de potencializá-lo a partir da relação entre diferentes atores que propõem, entre outros fatores, melhorias da condição profissional e acadêmica e a renovação das próprias práticas amparadas pelo rigor científico, mas também pela flexibilidade da experiência e de suas implicações nas práticas sociais, buscando assim impactos sociais e educacionais mais extensos.

Nesse sentido, com o objetivo de entender melhor os aspectos aqui tratados, apresentaremos o Mestrado Profissional em Gestão e Tecnologias Aplicadas à Educação (Gestec), que pode ser caracterizado como inovador não só pela própria estrutura desse tipo de curso, que, entre outras características, propõe-se a ser transdisciplinar, considerando aqui a transdisciplinaridade como "estágio em que se estaria conseguindo a unificação do conhecimento" (KLEIN, 1990 apud HOFF et al., 2007, p. 44), mas por ser o único mestrado profissional em educação na Bahia e buscar a conciliação entre a prática e a teoria, entre o estudo e suas consequências e entre o saber científico e a experiência, com vistas à melhoria na área educacional por meio Universidade Federal do Paraná - Funpar (http:// www.funpar.ufpr.br) da pesquisa aplicada. "Propõe-se que o Mestrado Profissional seja valorizado como experiência inovadora capaz de contribuir para a renovação da pós-graduação brasileira” (FISCHER, 2005, p. 24). 


\section{Inovação e mestrado profissional: o exemplo do Gestec}

O Programa de Pós-Graduação em Gestão e Tecnologias Aplicadas à Educação da Universidade do Estado da Bahia (Gestec/ Uneb) foi aprovado em 2010 e recomendado pela Capes por meio do Ofício nº 039 11/2010/CTC/CAAll/CGAA/DAV/CAPES. O referido programa iniciou suas atividades em 2011, com a implantação do primeiro mestrado profissional em educação no estado da Bahia.

O Gestec é um programa institucional, mas conta com a parceria de outras instituições de ensino superior do Brasil, além de instituições estrangeiras. Essas parcerias são desenvolvidas com o intuito de ampliar a inserção social e a difusão de formação qualificada para atuar nos ensinos básico e superior, salientando a relevância de um trabalho em rede que fomente processos consubstanciados pela busca de experiências que transcendam a esfera acadêmica, atingindo assim o debate profissional pertinente ao contexto sócio-histórico. Nesse sentido, o Gestec tem como principal finalidade:

[...] a produção de conhecimentos, a atualização permanente dos avanços da ciência e das tecnologias, a capacitação e o aperfeiçoamento de profissionais na área da gestão educacional e processos tecnológicos, bem como o desenvolvimento da pesquisa aplicada e a inovação tecnológica no campo da educação (UNEB, 2010b, p. 2).

A finalidade desse programa reitera a importância dele no cenário atual, visto que demonstra a necessidade de tratar de temáticas como ciência, tecnologia e inovação, integrando-as ao campo educacional e deixando claro que a educação deve aventar, propor e redimensionar essa tríade, ora estabelecida na nossa sociedade.

As concepções vigentes de educação sinalizam cada vez mais a urgência de buscar não apenas novas bases teórico-metodológicas para além das visões da ciência clássica que subsidiem uma transformação nas práticas pedagógicas, mas a construção de um pensamento educacional mais sintonizado com as exigências dos novos tempos (ARAÚJO, 2007, p. 517). 
Nesse sentido, a estruturação do Gestec potencializa essa discussão, pois oferece, por meio de suas áreas de concentração (a. Gestão da Educação e Redes Sociais e b. Processos Tecnológicos e Redes Sociais), temáticas e frentes de trabalho que valorizam o contexto social no qual a Educação está imbricada. Esses(as) eixos/ áreas de concentração são constituídos por linhas e grupos de pesquisa, além de núcleos de produção e desenvolvimento tecnológico, em que se possibilita a geração e realização de produtos e processos, como pesquisas, projetos, programas, experiências inovadoras, técnicas, aplicativos, materiais didáticos, entre outros.

O Gestec é um dos nove programas de pós-graduação vigentes na Uneb, além de ter o único mestrado profissional atualmente regulamentado pela Capes na instituição, o que proporciona para a universidade a imersão na realidade da pós-graduação brasileira, que vem, no decorrer dos anos, aumentando o número de mestrados profissionais e buscando a qualidade e excelência equiparada ao mestrado acadêmico, o que deve ser garantido pelos requisitos para implantação, desenvolvimento, avaliação e promoção de ambos.

Esse fato apresenta uma relevância basilar no que tange as próprias características da Universidade do Estado da Bahia, que é pioneira em extensão e multicampia, mas que vem paulatinamente conquistando o seu espaço e se consolidando no que concerne a pósgraduação stricto sensu.

Outro fator relevante apresentado pelos MP é o seu caráter interdisciplinar e multirreferencial. O Gestec apresenta essas características tanto no que se refere à formação acadêmica dos discentes (Gráfico 2 - Anexo) quanto dos docentes (Gráfico 3 - Anexo). A primeira turma a ingressar no programa totaliza o número de 50 alunos ${ }^{4}$, divididos nas mais diversificadas áreas de formação.

Dentre as áreas supracitadas, aparece, em sua maioria, a formação inicial em Pedagogia, representando 34\% do alunado e 46\% do

4 O Gestec é um programa recém-lançado, estando em voga sua primeira turma. corpo docente. Esse dado, apesar de já ser esperado, devido ao mestrado ser em Educação, consegue em outras dimensões surpreender, visto 
que o número é relativamente pequeno se comparado à grande parte dos mestrados acadêmicos, em que predomina como formação dos alunos e professores a área de direcionamento do programa.

Ademais, esse predicado do Gestec propicia um pensar, agir e intervir por parte das diversas áreas, incidindo em um saber/ fazer próprio da Educação. Isso mostra, muito além do discurso, que a Educação é área fundamental e que deve perpassar por todos os caminhos, afinal, o que seria da formação profissional sem a formação educativa?

Essa parceria entre as diferentes áreas possibilita transcender a reunião de especialistas em determinados temas, proporcionando a criação de um espaço de debate e ação contextualizada, uma busca infindável pela superação dos limites do conhecimento fragmentado para atingir um processo complexo, assinalado pela diversidade, pelo respeito e pelo desenvolvimento de um ambiente transformativo e qualitativamente produtivo, por isso, inovador.

A questão do conhecimento, portanto, não é relativa à redução de pontos de vista, mas, ao contrário, à interação entre modalidades de conhecimento e formas de atribuição de significado, enquanto vivência sócio-histórica e, por isso mesmo, relativa a contextos, os quais também se intercruzam, combinam-se, assemelham-se, diferenciamse, complementam-se, divergem, etc. (LIMA JR, 2007, p. 184).

Diante disso, percebemos a heterogeneidade, a diversidade de referências e o respeito aos saberes diversificados como ponto crucial para a superação dos velhos paradigmas, salientando que não é preciso construir outros paradigmas, pois pensar o conhecimento por meio da variedade contextual dos sujeitos não permite criar modelos fechados e lineares, afinal, o ser humano, e a dinâmica que o permeia, não é passivel de ser mensurado, analisado e tampouco enquadrado.

Não é possível falar de pós-graduação sem citar a pesquisa como ponto crucial nesse percurso, independentemente do nível ou modalidade, por isso, basilar na discussão estabelecida nesse trabalho. 
A pesquisa possibilita e é a base para a promoção e manutenção da pós-graduação. Em um Mestrado Profissional, apesar da ideia tônica, ela é fundamental, pois garante o aprofundamento necessário a um curso de pós-graduação, além de ser o motor para a geração de tecnologias, em sua forma ampla, e sua transferência, alcançando assim a inovação.

No que se refere ao Gestec, a parceria entre pesquisa e pósgraduação estabelece caminhos para a formação de profissionais na área de Educação com vistas à geração de resultados e impactos no campo educacional.

Nesse âmbito, tratamos a inovação como um processo passível às diversas áreas do saber, mas até que ponto esse assunto ainda é tratado como algo restrito a determinadas áreas do conhecimento?

Segundo os dados do Diretório de Grupos de Pesquisa do CNPQ, existem 165 grupos de pesquisa certificados pela instituição (Uneb), em que predomina a área de Ciências Humanas (Gráfico 4 - Anexo).

Os dados esboçados no gráfico demonstram a preponderância da área de Ciências Humanas, expressando o potencial da universidade na formação de profissionais para a docência. Essa realidade é vista por muitos como uma dificuldade na produção de inovação, visto que a cultura da inovação está ainda muito voltada ao setor produtivo e ao desenvolvimento de tecnologias que gerem lucro. Contudo, a inovação surge também da necessidade e da criatividade de sujeitos ou grupos que buscam alternativas para a minimização ou solução de problemas, assim como investem em outros caminhos e mecanismos para orientar e realizar determinadas ações. A criação de uma nova metodologia de pesquisa, assim como o aproveitamento de um produto típico de uma região para a comercialização e geração de renda para aquela comunidade, também pode ser entendida como inovação.

As leis de proteção à propriedade intelectual (PI) - Lei da Propriedade Industrial/Lei de Proteção aos Cultivares, Lei de Programas de Computador, entre outras - são, em sua maioria, 
vinculadas a criações específicas. Esse fato acaba restringindo o número de produções passíveis de registro nos órgãos responsáveis pela proteção à PI. Essa restrição faz com que muitos pesquisadores acreditem que só é inovador aquilo que tem a garantia de proteção com base nessas leis.

Contudo, buscamos apontar o tema inovação a partir de um contexto mais amplo, em que as boas ideias geradas na universidade podem acarretar impactos de grande relevância para a sociedade, mesmo quando não patenteáveis.

Essa afirmação não visa contrapor ou negar a importância do registro das criações, todavia, vem demonstrar que é possível somar a isso outras tendências, assumindo as distintas perspectivas e apoiando a necessidade de transcender os discursos estabelecidos.

Os MP, principalmente aqueles que perpassam pelo ensino, como é o caso do Gestec, vêm para demonstrar que é possivel inovar a partir da consistência entre o intelecto e a ação, revelando que esses fatores, quando integrados, suscitam mudanças e efeitos muito acentuados, imergindo, inclusive, no campo da produção científicoacadêmica, mas também na geração de processos caracterizados pelo seu cunho inovador, direcionado ao ensino e a seus componentes, como o currículo, a coordenação e a orientação formativa, a gestão, a avaliação e as práticas pedagógicas.

Ressalvamos a importância dos profissionais/pesquisadores, que são formados nos MP como sujeitos multiplicadores do fazer com esse cunho inovador. A experiência do Gestec, principalmente no que diz respeito ao modo como a tecnologia aplicada à Educação é tratada, considerando-a não apenas um artefato ou recurso, mas um processo criativo e transformativo criado pelo homem para atingir seus desejos e suas necessidades, possibilita que esse programa seja considerado como uma experiência inovadora, tanto a partir de sua estrutura como pela sua base teórica, permitindo que o educando possa exercer o (re) pensar sobre a complexidade do social nas relações, entendendo as diversas matrizes presentes na prática pedagógica, buscando colaborar para a produção do saber e a disseminação de ideias e práticas que resultem em diferentes processos configurados como inovação. 
Partindo dessa perspectiva, o Gestec reforça a ideia de que o processo de inovação não ocorre em espaços pré-estabelecidos; tampouco, em áreas definidas. A inovação acontece, muitas vezes, nos lugares inesperados, a partir de estratégias simples e oriundas da necessidade e busca por soluções de problemas cotidianos.

\section{Considerações finais}

O presente artigo se propôs a percorrer a trajetória do mestrado profissional no Brasil, assinalando as potencialidades inovadoras dessa modalidade de curso, assim como as dificuldades enfrentadas para o seu estabelecimento no âmbito acadêmico. Em paralelo, trouxemos o exemplo do Gestec, o primeiro mestrado profissional na área de Educação na Bahia, que visa, dentro desse contexto multicampi da Universidade do Estado da Bahia, desenvolver resultados com vistas à inovação no ensino, disseminando a importância da universidade absorver essas práticas ou aderir a elas.

Este breve estudo foi fundamental para que entendêssemos o quanto a cultura da inovação ainda é incipiente no País e precisa ser fomentada pelos NITs, Institutos de Ciência e Tecnologia (ICTs) e por todos os grupos que direta ou indiretamente já estão envolvidos no processo.

Ressalta-se a importância deste estudo como uma primeira etapa de discussões, considerando que é necessário retomá-lo em outra ocasião, buscando a interlocução com outras experiências e teorias, gerando questionamentos e reflexões que enriqueçam esse montante cada vez mais significativo na pós-graduação.

Ao tratar a inovação no âmbito do MP, estabelecemos determinadas discussões que incidem como categorias essenciais no desenvolvimento da pós-graduação. São elas: os mestrados profissionais como práticas inovadoras, a formação de sujeitos para a inovação e a inovação abordada em sentidos mais amplos.

Com o estudo realizado durante os primeiros meses do ano vigente, foi possível identificar os entraves pelos que o MP vem 
passando para se estabelecer no cenário educacional brasileiro, ao mesmo modo que diversas experiências foram pesquisadas, mostrando que ações estão sendo desenvolvidas para superar esses problemas e alcançar a qualidade desejada.

A partir dos documentos provenientes do Gestec, tais como projeto de implantação (UNEB, 2010a) e regimento (UNEB, 2010b), assim como entrevistas com a coordenação e os corpos docente e discente, foi possível entender, sumariamente, a dinâmica que permeia o MP, especificamente na área educacional.

Observamos ainda a necessidade de contínuo debate entre os programas de pós-graduação, tanto a nível interno como externo. Afinal, esse debate proporciona um trabalho em rede que, na maioria das vezes, não é estabelecido sequer dentro da mesma instituição. As áreas do conhecimento não costumam relacionar-se umas com as outras, e essa perspectiva sugere que medidas sejam tomadas para gerar esse alinhamento. Esse alinhamento não ocorrerá apenas com críticas às posições alheias, mas a partir da superação dos próprios limites e da busca efetiva por formas outras de fazer a mudança e alcançar novas configurações dentro da universidade.

Não a fim de constituir modelos, mas com o intuito de gerar possiveis soluções, apontamos o fortalecimento das ações de integração entre as diferentes áreas do conhecimento como uma alternativa coerente dentro do contexto que se aventa. Essa integração deve, primeiramente, respeitar as peculiaridades advindas de cada área, somando os pontos de destaque a aqueles menos tratados, com o intuito de subverter a atual realidade e percorrer caminhos mais dialógicos.

Em seguida, trazemos a importância da difusão da inovação na universidade, possibilitando que todos os atores tenham acesso a ela de uma forma ampla, superando assim as restrições muitas vezes encontradas.

Em relação ao Gestec, iteramos seu teor inovador por inserir processos pedagógicos que suplantam as "velhas" práticas da 
universidade, permitindo-se o risco e as tentativas, que são, sem dúvida, o primeiro passo para atingir o novo, as transformações e as conquistas no âmbito da teorização e da prática.

Por fim, esperamos que as reflexões aqui expostas possam contribuir para debates futuros acerca da relevância dos cursos de MP para o processo de inovação, visto que o conhecimento deve ser tratado também de forma desfragmentada e aplicada. Ademais, ressaltamos a necessidade de aperfeiçoamento dos critérios de aprovação e avaliação no que concernem os cursos de MP, garantindo uma estrutura curricular e uma proposta de produção voltadas à inovação em seus diferentes parâmetros e conforme as especificidades presentes nessa modalidade de curso de pós-graduação.

\section{Notas}

Ministério de Ciência e Tecnologia. Manual de Oslo: proposta de diretrizes para coleta e interpretação de dados sobre inovação tecnológica. 2004, 136p. In: MARTINS, C. B.; ASSAD, A. L. D. (2008, p. 328): "O processo de inovação inclui todos os passos necessários - técnicos, gerenciais, comerciais e financeiros - para introduzir um produto ou processo, ou mesmo um serviço, novo ou aperfeiçoado, no mercado. A inovação também é definida como uma combinação de necessidades sociais e de demandas do mercado com o meio científico e tecnológico para resolvê-las; fazendo parte, dessa forma, atividades científicas, tecnológicas, produtivas, de distribuição, financeiras e comerciais. É uma atividade complexa e diversificada em que os vários componentes interagem, no qual a geração de conhecimentos e sua aplicabilidade para o desenvolvimento econômico e social de um país passam a ser elementos centrais em todo o processo."

Recebido 31/03/2012 Aprovado 26/10/2012 


\section{Referências bibliográficas}

AGOPYAN, V.; LOBO, R. O futuro do Mestrado Profissional. RBPG, Brasília, v. 4, n. 8, p. 293 302, dez. 2007.

ARAÚJO, M. M. S. de. O pensamento complexo: desafios emergentes para a educação on-line. Revista Brasileira de Educação, v. 12, n. 36, p. 515-551, set./dez., 2007. Disponivel em: <http://www.scielo.br/pdf/ rbedu/v12n36/a10v1236.pdf>. Acesso em: 17 mar. 2012.

BARROS, L. V. Notas sobre o Mestrado Profissionalizante: a experiência do Centro de Desenvolvimento Sustentável da UnB. RBPG, v. 5, n. 10, p. 353-364, dez. 2008.

BRASIL. Lei $n^{\circ}$ 10.973, de 2 de dezembro de 2004. Dispõe sobre incentivos à inovação e à pesquisa científica e tecnológica no ambiente produtivo. Diário Oficial [da] República Federativa do Brasil, Poder Executivo, Brasília, DF, dez. 2004.

CAPES - Coordenação de Aperfeiçoamento de Pessoal de Nivel Superior. Portaria n 80, de 16 de dezembro de 1998. Dispõe sobre o reconhecimento dos mestrados profissionais e dá outras providências. Diário Oficial [da] República Federativa do Brasil, Brasília, DF, 11 jan. 1999. N 6, seção 1, p. 14.

CASTRO, C. de M. A hora do mestrado profissional. RBPG, Brasília, v. 2, n. 4, p. 16-23, jul. 2005.

DESSEN, M. A. da S. C. Sessão de Abertura do IV Encontro do Fórum Nacional dos Mestrados Profissionais. In: ENCONTRO DO FÓRUM NACIONAL DOS MESTRADOS PROFISSIONAIS, 4., 2008, Canoas. Anais... Canoas: Universidade Luterana do Brasil, 2008.

FISCHER, T. Seduções e riscos: a experiência do mestrado profissional. Revista de Administração de Empresas [online], v. 43, n. 2, p. 119123, abr./jun. 2003. Disponivel em: <http://www.scielo.br/scielo. php?pid=S0034-75902003000200010\&script=sci_arttext $>$. Acesso em: 03 mar. 2012. 
Mestrado Profissional como prática acadêmica. RBPG, Brasília, v. 2, n. 4, jul. 2005 .

Tréplica - Reimaginar a Pós-Graduação: resgatando o elo perdido. Documentos e Debates, Curitiba, v. 14, n. 2, p. 372-376, mar./ abr. 2010. Disponível em: <http://www.anpad.org.br/periodicos/ content/frame_base.php?revista=1>. Acesso em: 18 mar. 2012.

FREITAS, F. T. Mais algumas notas sobre a transição da pós-graduação brasileira. RBPG, Brasília, v. 8, n. 15, mar. 2011.

HOFF, D. N. et al. Os desafios da pesquisa e ensino interdisciplinares. RBPG, Brasília, v. 4, n. 7, jul. 2007.

LIMA JR., A. S. de. Tecnologias inteligentes e educação: currículo hipertextual. Rio de Janeiro: Quartet, 2007.

MARTINS, C. B.; ASSAD, A. L. D. A pós-graduação e a formação de recursos humanos para inovação. RBPG, Brasília, v. 5, n. 10, p. 322-352, dez. 2008.

MOREIRA, M. A. O mestrado (profissional) em ensino. RBPG, Brasília, v. 1, n. 1, p. 131 - 142, jul. 2004.

MORIN, E. Introdução ao pensamento complexo. Porto Alegre: Sulina, 2005.

NEGRET, F. A identidade e a importância dos mestrados profissionais no Brasil e algumas considerações para a sua avaliação. RBPG, Brasília, v. 5, n. 10, p. 217-225, dez. 2008.

PACHECO, C. A. Desafios da inovação, incentivos para inovação: o que falta ao Brasil. São Paulo: IEDI, 2010. Disponível em: <http:/ /www.iedi. org.br/admin_ori/pdf/20100211_inovacao.pdf>. Acesso em: 30 mar. 2012.

UNEB - Universidade do Estado da Bahia. Programa de Pós-Graduação em Gestão e Tecnologias Aplicadas à Educação. Projeto de Implantação GESTEC. Salvador, 2010a. 
Programa de Pós-Graduação em Gestão e Tecnologias Aplicadas

à Educação. Regimento Gestec, Salvador, 2010b. 24 p.

RIBEIRO, R. J. Ainda sobre o mestrado profissional. RBPG, Brasília, v. 3, n. 6, p. 313-315, dez. 2006.

SANTOS, B. de S. Um discurso sobre as ciências. São Paulo: Cortez, 2003.

\section{Anexos}

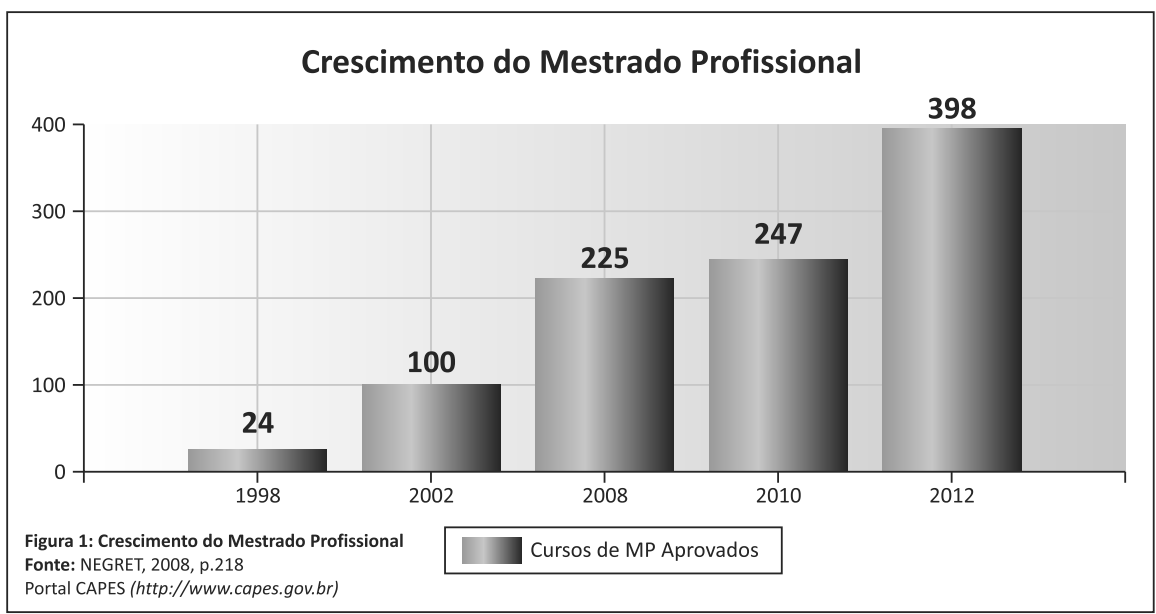

Gráfico 1. Crescimento do mestrado profissional

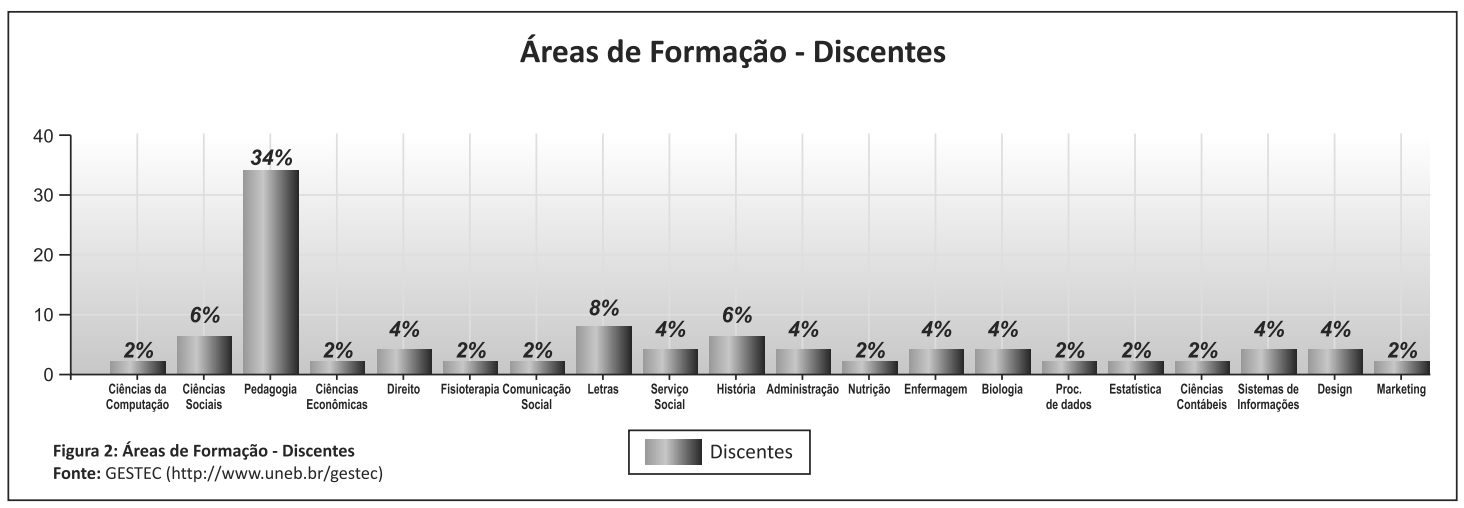

Gráfico 2. Áreas de formação: discentes do Gestec 


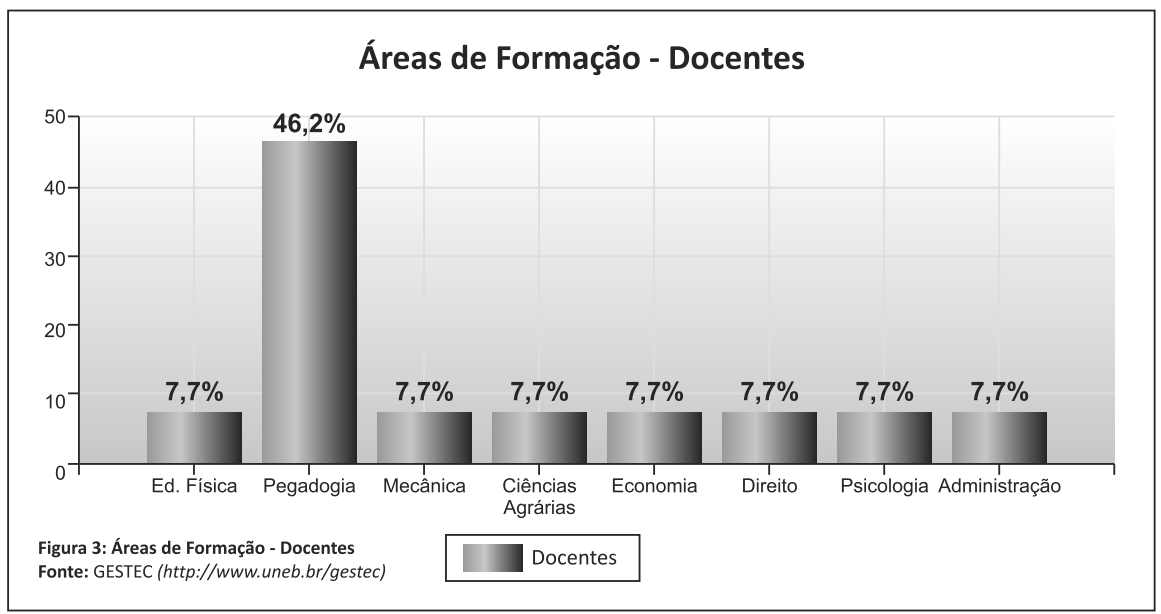

\section{Gráfico 3. Áreas de formação: docentes do Gestec}

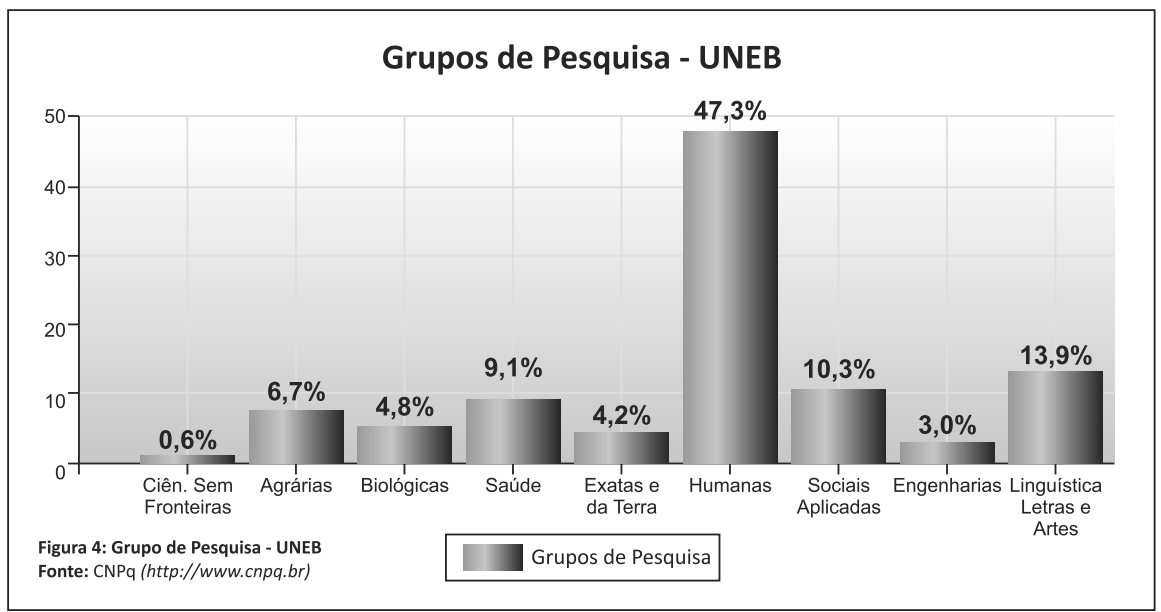

Gráfico 4. Áreas do conhecimento: grupos de pesquisa da Uneb 